\title{
Ourivesaria, Joalharia e Relojoaria: principais Riscos e Fatores de Risco Laborais, Doenças Profissionais associadas e medidas de proteção recomendadas
}

1 www.rpso.pt/ourivesaria-joalharia-e-relojoaria-principais-riscos-e-fatores-de-risco-laborais-doencas-profissionais-

associadas-e-medidas-de-protecao-recomendadas/

January 4, 2017

GOLDSMITHS, JEWELERS AND WATCHES PRODUCTORS: MAIN RISKS AND RISK FACTORS, PROFESSIONALS DISEASES AND RECOMMENDED PROTECTIVE MEASURES

TIPO DE ARTIGO: Revisão Bibliográfica Integrativa

AUTORES: Santos M(1), Almeida A(2).

\section{RESUMO}

\section{Introdução/ enquadramento/ objetivos}

Este setor inclui a produção de relógios (e acessórios), moedas, filigrana e joias (incluindo eventualmente a inserção e trabalho de pedras semi-preciosas ou preciosas). As principais etapas são a fundição em chapa ou fio ou injeção de moldes e eventualmente laminagem, trefilação, maquinação, banhos, polimento, autenticação ("contraste") e embalagem. No decorrer destes processos os profissionais deste setor estão sujeitos a diversos riscos/ fatores de risco, alguns dos quais pouco divulgados; para além disso, a generalidade da bibliografia consultada aborda riscos específicos e parcelares (e é escassa), não sendo fácil encontrar uma perspetiva global, a nível de Saúde Ocupacional.

\section{Metodologia}

Os artigos foram selecionados pelo método PICo. Foi realizada uma pesquisa em setembro de 2016 nas bases de dados "CINALH plus with full text, Medline with full text, Cochrane Central Register of Controlled Trials, Cochrane Database of Systematic Reviews, Cochrane Methodology Register, Nursing and Allied Health Collection: comprehensive, MedicLatina e Academic Search Complete", bem como na base de dados RCAAP.

\section{Conteúdo}

Estes trabalhadores estão por vezes expostos a diversos agentes químicos (com destaque para a silicose, níquel, nitratos, cloreto de amónio, corantes com anilina, aqua regia e cádmio); poderão também apresentar posturas mantidas e movimentos repetitivos (o que poderá originar lesões músculo-esqueléticas); os turnos poderão ser prolongados e a iluminância desadequada.

\section{Conclusões}


Os principais fatores de risco associados a estes setores profissionais são a nível de exposição a agentes químicos, questões ergonómicas (posturas mantidas, movimentos repetitivos) e o esforço visual. A nível de doenças profissionais (para além das questões músculo-esqueléticas associadas) é dado realce à silicose.

Palavras-chave: ourivesaria, ourives, joalharia, relojoaria, saúde ocupacional, medicina do trabalho.

\section{SUMMARY}

\section{Introduction / Framework / Objectives}

This sector includes the production of watches (and accessories), coins, filigree and jewelry (including possibly the insertion and work of semi-precious or precious stones). The main steps are sheet or wire casting or injection of molds and eventually rolling, drawing, machining, bathing, polishing, authentication ("contrast") and packaging. In the course of these processes the professionals in this sector are subject to several risks / risk factors, some of which are not widely disclosed; In addition, the generality of the bibliography consulted addresses specific and partial risks (and is scarce), and it is not easy to find a global perspective, at Occupational Health level.

Methodology The articles were selected using the PICo method. A search was conducted in September 2016 in the databases "CINALH plus with full text, Medline with full text, Cochrane Central Register of Controlled Trials, Cochrane Database of Systematic Reviews, Cochrane Methodology Register, Nursing and Allied Health Collection: comprehensive, MedicLatina And Academic Search Complete "as well as the RCAAP database.

Content These workers are sometimes exposed to various chemical agents (notably silicosis, nickel, nitrates, ammonium chloride, dyes with aniline, aqua regia and cadmium); May also present sustained postures and repetitive movements (which may lead to musculoskeletal injuries). The shifts may be prolonged and the illumination inadequate.

Conclusions The main risk factors associated with these professional sectors are exposure to chemical agents, ergonomic issues (maintained postures, repetitive movements) and visual effort. In terms of occupational diseases (in addition to associated musculoskeletal issues), silicosis is highlighted.

Keywords: goldsmiths, jewelry, watchmaking, occupational health, occupational medicine.

\section{INTRODUÇÃO}

Os profissionais a trabalhar em equipas de Saúde Ocupacional, mesmo que não diretamente ligados a este setor, podem receber trabalhadores com esses antecedentes laborais, pelo que poderão sentir necessidade de aprofundar um pouco os seus conhecimentos na área. Os profissionais deste setor estão sujeitos a diversos riscos/ fatores de risco, alguns dos quais pouco divulgados; para além disso, a generalidade da bibliografia consultada aborda riscos específicos e parcelares, não sendo fácil encontrar uma perspetiva global, a nível de Saúde Ocupacional. 


\section{METODOLOGIA}

Pergunta protocolar: Quais os principais riscos e fatores de risco existentes para os profissionais do setor da Ourivesaria, Joalharia e Relojoaria, eventuais doenças profissionais associadas e medidas de proteção recomendadas?

Em função da metodologia PICo, foram considerados:

-P (population): profissionais do setor da Ourivesaria, Joalharia e Relojoaria

-I (interest): adquirir mais conhecimentos sobre os principais riscos e fatores de risco existentes para os profissionais do setor da Ourivesaria, Joalharia e Relojoaria, eventuais doenças profissionais associadas e medidas de proteção recomendadas, segundo os dados mais recentemente publicados

-C (context): saúde ocupacional nas empresas de Ourivesaria, Joalharia e Relojoaria

Foi realizada uma pesquisa em setembro de 2016 nas bases de dados "CINALH plus with full text, Medline with full text, Cochrane Central Register of Controlled Trials, Cochrane Database of Systematic Reviews, Cochrane Methodology Register, Nursing and Allied Health Collection: comprehensive, MedicLatina e Academic Search Complete". Utilizando as palavras-chave "goldsmith", "jewelry" e "horology" foram obtidos 680, 569 e 0 artigos, com os critérios publicação igual ou superior a 2006 e acesso a texto completo; conjugando tal com a palavra-chave "occupational", obtiveram- se 35, 27 e 0 artigos; em função da língua original (portuguesa, inglesa ou espanhola) e da pertinência para o objetivo desta revisão, foram selecionados 2, 14 e 0 após a leitura do resumo e, após a consulta do trabalho na íntegra, manteve-se o interesse em 2, 11 e 0 desses artigos.

Contudo, como não se encontram estudos relativos à realidade portuguesa nestas bases de dados indexadas, os autores procuraram trabalhos inseridos no RCAAP (Repositório Científico de Acesso Aberto em Portugal). Aqui, utilizando as palavras-chave "relojoaria, ourivesaria, ourives, joalharia, joia, prata, ouro e filigrana", foram obtidos 2, 19, 12, 14, 18, 733, 743 e 2 documentos; após a leitura do resumo dos mesmos não foram selecionados quaisquer artigos.

O resumo da metodologia aplicada nesta revisão pode ser consultado nos fluxogramas de $1^{a}$ e $2^{a}$ fases. A caraterização metodológica e resumo dos artigos selecionados está inserida no quadro 1.

Dada a escassez de artigos foi ainda incluído um documento criado pela ACT relativo a este setor, disponível em qualquer motor de busca generalista.

\section{CONTEÚDO}

Este setor inclui a produção de relógios (e acessórios), moedas, filigrana e joias (incluindo eventualmente a inserção e trabalho de pedras semi-preciosas ou preciosas). As principais etapas são a fundição em chapa ou fio ou injeção de moldes e eventualmente laminagem, trefilação, maquinação, banhos, polimento, autenticação ("contraste") e embalagem1. Os principais riscos deste setor podem ser estratificados consoante registado no Quadro 2. 
O cádmio é um metal tóxico frequentemente usado na Ourivesaria tradicional ${ }^{2,3}$, sobretudo para trabalhar/ moldar o ouro ${ }^{3}$ e a prata ${ }^{4,5}$. As peças de prata, por exemplo, chegam a ter $30 \%$ deste elemento. A exposição ocorre quer na elaboração da peça, quer no seu polimento, sobretudo devido à inalação de fumo/ poeira. Na bibliografia estão descritos danos agudos e crónicos, nomeadamente a nível renal ${ }^{5}$, cardiovascular $^{2,3}$, respiratório ${ }^{2-4}$ (como enfizema, devido à destruição da arquitetura alveolar ${ }^{2,4}$ ) e neuropsiquiátrico; alguns autores descrevem que a densidade óssea pode ser alterada ${ }^{5}$. Algumas investigações também alertam para a associação com patologia oncológica pulmonar, renal, prostática e pancreática- aliás a IARC (International Agency for Research on Cancer) considerou-o, em 1992, como carcinogénico do grupo $\mathrm{I}^{2}$. Ainda dentro das alterações respiratórias, um estudo que seguiu 133 ourives indianos conclui que estes apresentavam diminuição da função respiratória e semiologia associada a tal condição ${ }^{4}$. A nefrotoxicidade, por sua vez, poderá ser manifestada pela insuficiência renal progressiva associada à disfunção glomerular e dos tubos renais proximais ${ }^{5}$.

Para além disso, alguns autores salientam que neste setor não é raro o uso de nitratos, cloreto de amónio, corantes com anilina e aqua regia ${ }^{6}$ (ácido nítrico e ácido clorídrico); contudo, nenhum dos artigos selecionados desenvolveu as eventuais consequências médicas destas exposições. Procurando tal informação em motores de busca generalista verificou-se que os nitratos, por exemplo, poderão alterar as propriedade da hemoglobina e/ou serem carcinogénicos. O cloreto de amónio, por sua vez, é irritante para os olhos, pele e vias respiratórias. A anilina pode originar alterações a nível dos glóbulos brancos e vermelhos. Por fim, mesmo em fichas de segurança do produto "aqua regia", os dados relativos às consequências médicas da inalação são escassos, referindo contudo a possibilidade de queimadura na boca e orofaringe (em caso de ingestão) e eventual irritação ocular.

A intolerância ao níquel tem sido cada mais diagnosticada (mesmo contanto com o efeito benéfico que a legislação conseguiu ao reduzir a concentração deste em vários produtos), não só entre a população geral (através do contato com joias, implantes dentários e outros dispositivos médicos, botões da roupa, moedas, instrumentos) ... como também é especialmente prevalente entre os trabalhadores associados à produção de objetos em metal, sobretudo com tarefas ligadas a fornos (risco 1,75 superior) ${ }^{7}$. Apesar de nenhum dos artigos selecionados ter relatado as consequências médicas deste produto, estas incidem sobretudo na irritabilidade cutânea e reações asmatiformes. A maior toxicidade ocorre perante a interação com o monóxido de carbono, originando carboneto de níquel; a semiologia mais frequente é caraterizada por cefaleias, náusea, vómito, tosse e hiperpneia. Alguns autores também o associam a patologia oncológica pulmonar e das estruturas nasais.

\section{-Dimensão Ergonómica}

Diversas tarefas neste setor profissional exigem posturas mantidas e/ou forçadas; uma disposição ergonómica menos correta potenciará ainda mais a ocorrência de lesões músculo-esqueléticas e o desconforto. Por fim, a baixa iluminância também poderá intensificar este fator de risco 6 . 
O facto de se utilizarem peças de pequena dimensão colocadas manualmente na joia e/ou se usarem ferramentas para o seu manuseamento, tal pode justificar o aparecimentos destas lesões ${ }^{8}$, sobretudo pela repetição de movimentos, sobretudo a nível da mão, punho e antebraço ${ }^{8}$.

Para além disso, a precisão necessária a estas tarefas exige que o trabalhador use sempre a mão com maior coordenação ${ }^{8}$, ou seja, nunca poderá trocar o uso da mão esquerda pela direita e vice-versa.

Em alguns subsetores é também frequente o manuseamento de cargas e, quando estas são depositadas no chão, também podem ocorrer quedas ao mesmo nível por tropeçarem nas mesmas.

Com os métodos mais artesanais para trabalhar o ouro é frequente a atividade de sopro para o modelar à forma desejada. Este procedimento, além de moroso, também exige a produção de uma pressão positiva através de um fluxo expiratório controlado, o que facilmente poderá induzir astenia a nível da musculatura facial (sobretudo no bucinador e no orbicular da boca), manifestada por tremor e dor, bem como alterações respiratórias (transpostas nas provas de função associadas) ${ }^{6}$.

\section{-Esforço visual}

Algumas tarefas neste setor são muito minuciosas e/ou envolvem o manuseamento de peças de dimensão muito pequena e, geralmente, com o uso de turnos prolongados, pelo que não é raro o desconforto visual ${ }^{6,9,10}$. A situação piora ainda mais com baixa iluminância, diminuta frequência de piscar de olhos (e consequente maior secura ocular), ângulos visuais restritos, convergência próxima e contrastes desadequados ${ }^{9,10}$. Contudo, alguns autores concluíram que apesar da exigência visual e das queixas subjetivas de cansaço, não foram encontradas patologias concretas, nas investigações realizadas pelos próprios ${ }^{9}$.

Um estudo indiano investigou uma amostra de crianças que trabalhava como lapidadoras e verificaram que estas, quando comparadas com os controlos, apresentavam maior prevalência (1,4 vezes superior) de cansaço visual, prurido ocular, desconforto/ sensação de queimor/ irritabilidade ocular, lacrimejo, visão turva ou até diplopia; a semiologia era mais frequente nos maiores de 14 anos e no sexo feminino (1,47 vezes superior), eventualmente pela maior exposição e por serem dadas piores condições de trabalho e ausência de acesso a cuidados médicos aos indivíduos desse género; para além disso, estas meninas também costumam auxiliar as mães nas tarefas domésticas, nomeadamente na cozinha, onde são utilizados combustíveis pouco saudáveis e é frequente a exposição a agentes químicos que pode potenciar as alterações oculares. A não lavagem das mãos após o término do trabalho e não troca de roupa potencia ainda mais a exposição. De realçar que nesse pais considera-se que $10 \%$ da mão-de-obra desse setor é infantil ${ }^{10}$.

-Silicose e outras patologias respiratórias 
A forma cristalina da sílica designa-se por quartzo e neste podem existir outros constituintes misturados (que proporcionam diferentes propriedades, nomeadamente a cor $)^{11}$.

A exposição crónica à sílica também poderá potenciar a ocorrência de tuberculose e até, segundo alguns autores, de patologia oncológica pulmonar. Dado ser a pneumoconiose mais frequente a nível mundial, é objetivo da Organização Mundial de Saúde erradicar a mesma até $2030^{12}$.

A silicose é uma doença profissional lentamente progressiva que surge após exposição geralmente prolongada a poeiras com elevada concentração de sílica. Comparando este setor profissional com outros, alguns autores defendem que esta patologia é mais grave e progressiva em ourives. A patologia é irreversível, continua a progredir após a interrupção da exposição e é eventualmente fatal. Como não há tratamento eficaz, dever-se-á apostar na prevenção. Por exemplo, apenas considerando a Índia, estima-se que existam cerca de dez milhões de trabalhadores expostos. O atingimento respiratório costuma ser significativo quando os níveis de sílica são superiores a $0,1 \mathrm{mg} / \mathrm{m} 3$. A silicose crónica resulta de vinte ou mais anos de exposição; a aguda apenas de alguns meses; poderá ocorrer uma versão intermédia de quatro a oito anos, desde que a concentração seja elevada ${ }^{11}$.

Em países com menor desenvolvimento da Saúde Ocupacional (como na Índia, por exemplo) o EPI (equipamento de proteção individual) fornecido, por vezes, consistia numa máscara frágil que geralmente se rasgava após dois e três dias de uso, não sendo reposta pelo empregador com a frequência necessária. Para além disso, a nível de medidas de proteção coletiva, o local era limpo com uma frequência muito inferior à desejável; não era usual existir acompanhamento médico e os turnos eram geralmente prolongados ${ }^{11}$.

Numa amostra estudada as opacidades pulmonares eram predominantes nas bases e em alguns coexistia tuberculose. O diagnóstico surgiu, em média, aos 3,4 anos de exposição (sendo também mais frequente em tabagistas e ex-fumadores) ${ }^{11}$.

A ágata é uma pedra semipreciosa muito utilizada em alguns contextos no setor da joalharia; as poeiras resultantes do seu manuseamento contêm sílica (sobretudo nas etapas de corte e esmerilamento, cujas dimensões podem atingir os 2 a 5 micrómetros), pelo que estes trabalhadores apresentam uma incidência aumentada de silicose e bronquite crónica; a prevalência é tanto superior quanto menor a ventilação e menor for o uso de EPIs adequados. Num estudo iraniano de trabalhadores neste subsetor, quantificou-se que $12,9 \%$ apresentavam critérios de silicose, mais prevalente entre os maiores de 40 anos e com mais de 25 anos de exposição. Aliás, técnicas estatísticas de regressão múltipla demonstraram que o número de anos de exposição eram justamente a variável independente com maior peso. A semiologia mais frequente referida neste estudo foi a dispneia, tosse e a expetoração. Nesta amostra apenas 1,1\% apresentava simultaneamente tuberculose (contudo, esta apenas era registada após informação oral dada pelo próprio e não através de qualquer teste), 11,7\% apresentava bronquite crónica e quase $5 \%$ referia sintomas compatíveis com asma. As alterações restritivas no padrão respiratório geralmente surgem antes das alterações radiológicas ${ }^{12}$. 
Outros estudos avaliaram os cortadores de diversas pedras usadas na joalharia (lapidadores) e também verificaram a existência de alterações cardíacas e respiratórias (com destaque num estudo no Sri Lanka para alterações restritivas genéricas, asma e o cancro pulmonar) ${ }^{13}$.

Acidentes de Trabalho

Segundo alguns investigadores, os principais acidentes de trabalho neste setor estão associados a cortes, queimaduras e quedas. Contudo, não foi dado grande destaque a esta questão entre os artigos selecionados.

Doenças Profissionais

Excetuando a silicose, não foi dada grande relevância a este tema nestes setores profissionais.

\section{CONFLITOS DE INTERESSE}

Não se aplicam.

\section{AGRADECIMENTOS}

Não se aplicam.

\section{CONCLUSÕES}

Os principais fatores de risco destes setores profissionais estão associados a agentes químicos, questões ergonómicas (posturas mantidas, movimentos repetitivos) e o esforço visual. A nível de doenças profissionais (para além das questões músculo-esqueléticas associadas) é dado realce à silicose.

Seria interessante que as Equipas de Saúde Ocupacional a laborar nesta área investigassem o tema e publicassem dados associados ao seu trabalho.

\section{BIBLIOGRAFIA}

1-ACT. Prevenir: Prevenção como solução. Manual de Boas práticas- Indústria da Joalharia, Ourivesaria e Relojoaria- 2011, 1-325.

2-Moitra S, Chakraborty K, Bhattacharyya A, Sahu S. Impact of Occupational Cadmium Exposure on spirometry, sputum leukocyte count and lung cell DNA damage among Indian Goldsmiths. American Journal of Industrial Medicine. 2015, 58, 617-625.

3-Moitra S, Brashier B, Sahu S. Occupational Cadmium exposure-associated oxidative stress and erithrocyte fragility among Jewerly workers in India. American Journal of Industrial Medicine.2014, 57, 1064-1072.

4-Moitra T, Blanc P, Sahu S. Adverse respiratory effects associated with cadmium exposure in small-scale jewellery workshops in India. Thorax. 2013, 68, 565-570.

5-Sethi P, Khandelwal D, Sethi N. Cadmium exposure: health hazards of silver cottage industry in developing countries. Journal of Medical Toxicology. 2006, 2(1), 14-16. 
6-Ghost T, Gangopadhyay S. Effect of an ergonomic intervention on muscle fatigue and respiratory stress of goldsmiths during blowing pipe activity in India. Work 43, 427-435.

7-Schran S, Warshaw E, Laumann A. Nickel hypersensitivity: a clinical review and call to action. International Journal of Dermatology. 2010, 49, 115-125.

8-Cândido P, Teixeira J, Moro A, Gontijo L. Biomechanical strain of Goldsmiths. Work 41. 2012, 2506-2509.

9-De A, Dhar U, Virkar T, Altekar C, Mishra W, Parmar V et al. A study of subjective visual disturbances in jewelry manufacturing. Work 41. 2012, 3404-3411.

10-Tiwari R, Saha A, Parikh J. Asthenopia (eyestrain) in working children of gem-polishing industries. Toxicology and Industrial Health. 2011, 27(3), 243-247.

11-Panchadhyayer P, Saha K, Saha I, Ta R, Ghosh S, Saha A et al. Rapidly Fatal Silicosis among Jewelry workers attending a district Medial College of West Bengal, India. Indian Journal of Chest Disease and Allied Science. 2015, 57, 165-171.

12-Rafeemenesh E, Majdi M, Ehteshamfar S, Fahoul M, Sadeghian Z. Respiratory Diseases in Agate Grinding Workers in Iran. International Journal of Occupational and Environmental Medicine. 2014, 5, 130-136.

13-Prathapan S, Hettiarachchi P, Wimalasekara S. Respiratory illness and ventilatory function among gem cutters in Sri Lanka. Ceylon Medical Journal. 2013, 58, 29-31.

Fluxograma $1^{\text {a }}$ fase

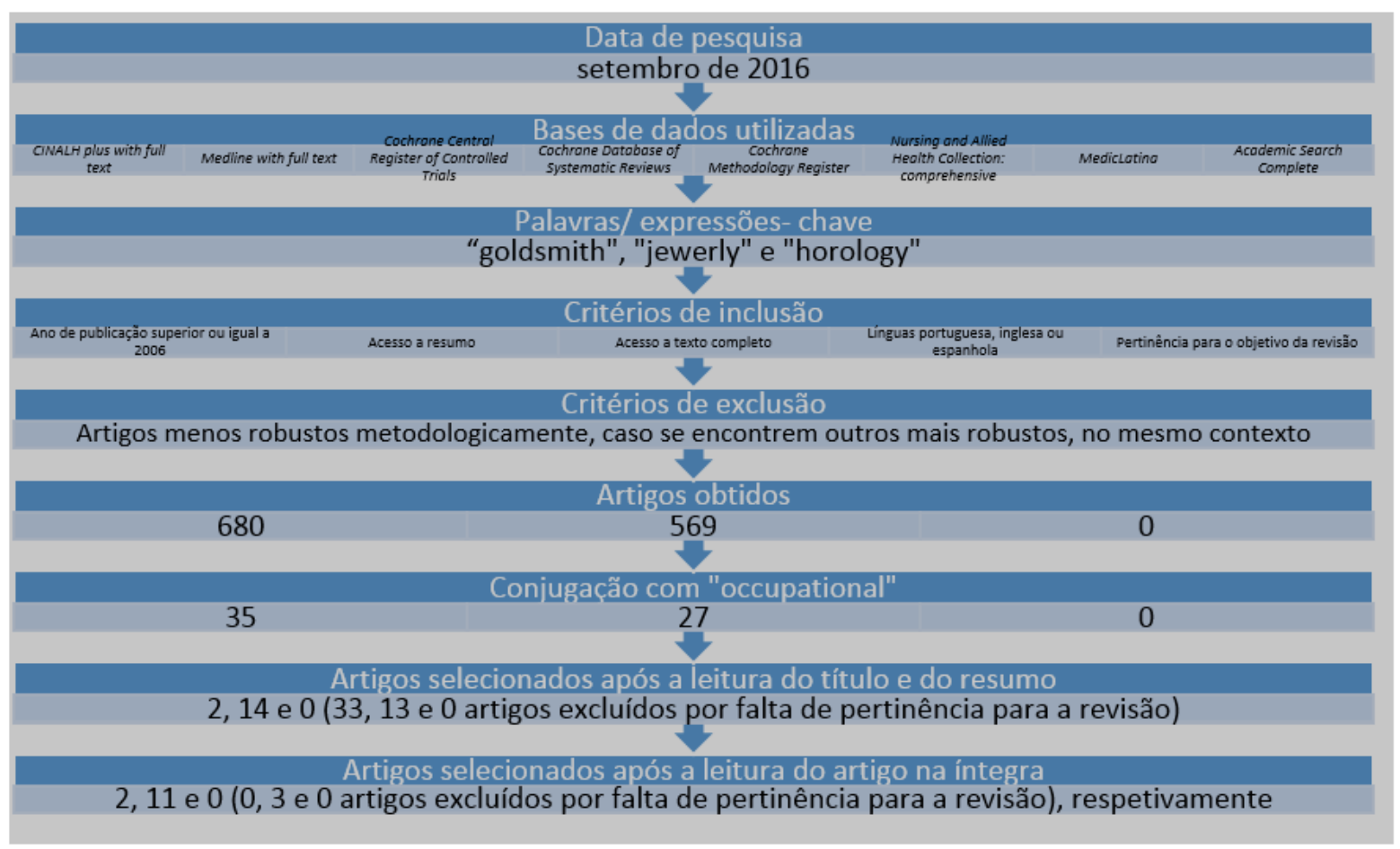

Fluxograma $2^{\mathrm{a}}$ fase 


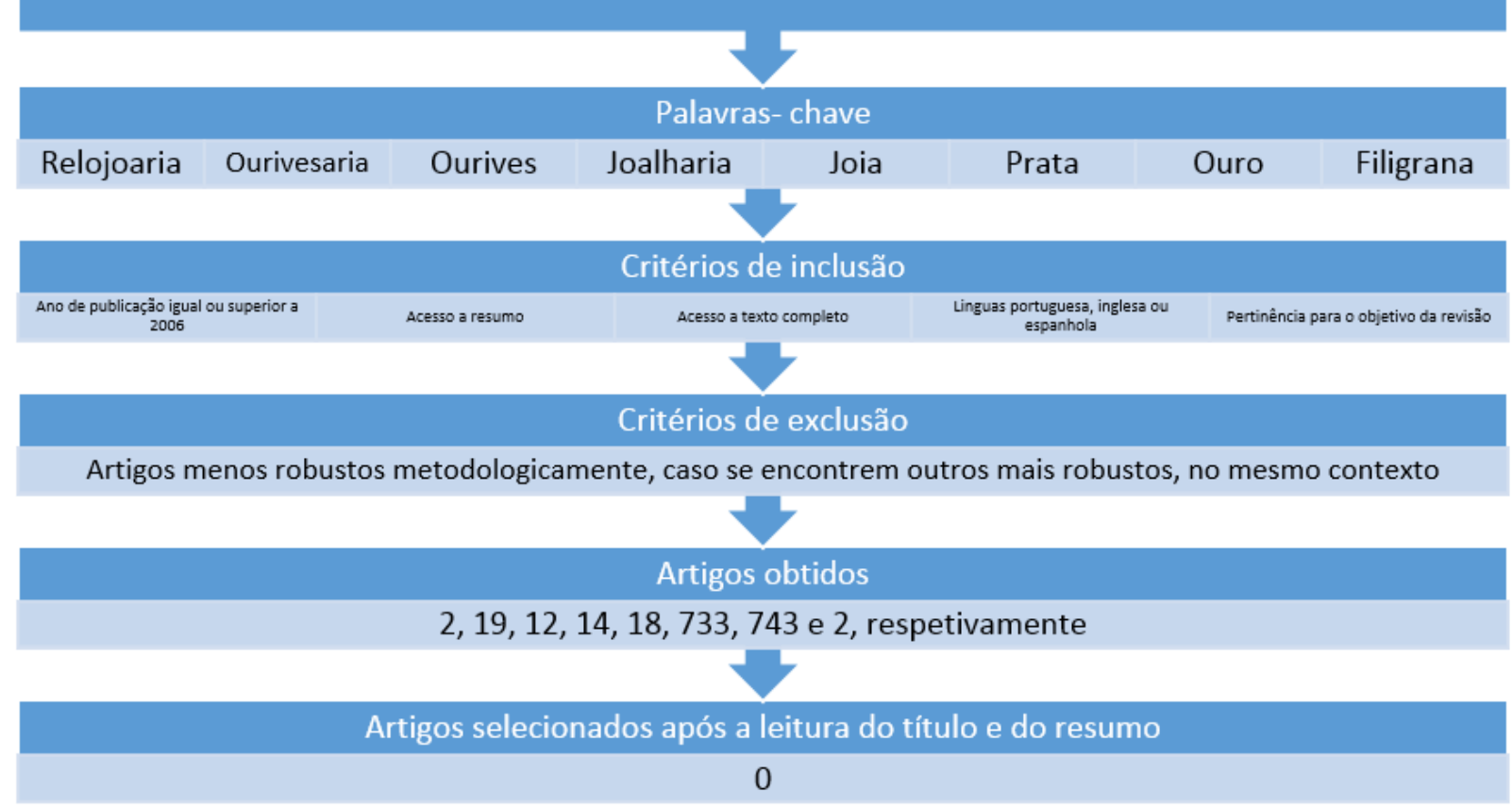

\section{Quadro 1- Classificação metodológica dos artigos consultados}

\begin{tabular}{ll} 
Artigo & $\begin{array}{l}\text { Tipo de } \\
\text { estudo }\end{array}$ \\
\hline 1 & Manual da ACT \\
\hline 2 & $\begin{array}{l}\text { Estudo de } \\
\text { Coorte }\end{array}$
\end{tabular}

\section{Resumo do estudo}

Neste trabalho foram seguidos 187 trabalhadores, num global de 276 , sendo que 133 destes trabalhava na ourivesaria, posteriormente comparados com 54 controlos de trabalhadores na área das vendas.

Os investigadores destacam que os efeitos tóxicos do cádmio estão razoavelmente bem descritos, ainda que não seja muito clara a fisiopatologia. Entre os que trabalhavam na ourivesaria, 26 estavam expostos a este agente e foram avaliados a nível de concentração urinária e sanguínea do mesmo, espirometria e leucograma.

Os indivíduos expostos a este agente com alterações da função pulmonar apresentavam aumento da resposta inflamatória e do dano celular a nível do DNA.

\section{Observacional}

Analítico

Transversal

Neste artigo foi realçada a toxicidade renal e pulmonar do cádmio, ainda que a fisiopatologia a nível do stress oxidativo e danos hematológicos não esteja totalmente clara. Foram avaliados os seguintes parâmetros entre trabalhadores deste setor expostos (32) e não expostos a este agente (21): concentração urinária de cádmio, enzimas plasmáticas antioxidantes (superóxido dismutase e catalase), peroxidação lipídica e fragilidade eritrocitária. Os autores concluíram que a presença deste agente contribuía para o stress oxidativo e danos eritrocitários.

4 Observacional Esta investigação salientou a toxicidade pulmonar do cádmio. Foram Analítico avaliados 133 ourives expostos ao agente e 54 ourives não expostos, Transversal relativamente a sintomatologia, espirometria e concentração urinária do cádmio. Encontrou-se correlação entre as intensidades da exposição e da sintomatologia.

$5 \quad$ Estudo de caso

Neste trabalho os autores salientam o facto de na produção de peças em prata usa-se o cádmio, que facilmente é inalado pelo trabalhador, através dos fumos produzidos; sendo que este agente é conhecidamente nefro e neurotóxico, estando também associados danos na densidade óssea. 
Observacional Aqui é destacado o facto de alguns ourives na Índia usarem frequentemente Analítico

Transversal um instrumento ("pipe") para o qual têm de produzir pressão positiva com expiração oral controlada, com intensidade e durante tempos prolongados, para dar forma ao objeto produzido. Os autores em causa pretenderam avaliar o stress pulmonar e a nível da musculatura facial. A amostra foi constituída por 100 ourives, avaliados através de questionário, espirometria e eletromiografia dos três principais músculos faciais. Este estudo concluiu que a aplicação de algumas medidas ergonómicas permitiriam atenuar os danos na musculatura facial e respiratórios.

$\begin{array}{lll}7 & \text { Revisão } & \text { A intolerância ao níquel tem vindo a aumentar, quer na população geral (por } \\ \text { Bibliográfica } & \begin{array}{l}\text { body piercing, questões ambientais, dispositivos médicos...), quer em } \\ \text { Narrativa }\end{array} & \begin{array}{l}\text { contexto laboral (sobretudo na indústria metalúrgica), mesmo com a } \\ \text { legislação progressivamente mais restritiva. }\end{array}\end{array}$

8 Observacional

Analítico

Transversal

Nesta investigação foi dado destaque aos movimentos repetitivos, exigentes na precisão e por vezes prolongados no tempo, em algumas atividades da ourivesaria. A quantificação e especificação dos mesmos foi realizada após visualizar um filme de uma hora para cada trabalhador analisado, ainda que a generalidade destes não apresentasse os sintomas tipicamente associados. Observacional
Analítico Transversal

O artigo em causa avaliou as alterações visuais subjetivas referidas em trabalhadores do setor da ourivesaria indiana, usando um questionário, dado algumas tarefas exigirem o manuseamento muito preciso de estruturas muito pequenas, usando 200 trabalhadores e 100 controlos. Não foram associadas patologias à sintomatologia apresentada.

10 Observacional A produção de joias de pequenas dimensões e/ou em locais com Analítico de iluminância desadequadas poderão contribuir para o cansaço visual, prurido, CasoControlo irritabilidade, diplopia, visão turna e cefaleia. A amostra foi construída a partir de 432 crianças que laboravam neste setor; os controlos eram formados por 569 crianças que não trabalhavam nesta área. Concluiu-se que as primeiras apresentavam um risco 1,4 vezes superior de desenvolver queixas oculares, mais prevalentes no sexo feminino.

Estudo de
Coorte

Os autores seguiram 27 pacientes seguidos numa instituição de saúde indiana por silicose, entre 2009 e 2012, trabalhadores em ourivesaria e noutros setores. Os autores concluíram que a patologia era mais grave e evoluía mais rapidamente no setor da ourivesaria.

Observacional A ágata é uma pedra semipreciosa razoavelmente usada para a produção Analítico Transversal de joias; algumas das tarefas produzem poeiras contendo sílica; foi objetivo deste estudo quantificar a prevalência das doenças respiratórias nestes trabalhadores. A amostra foi constituída por 170 iranianos e a estes foi aplicado um questionário; fez também espirometria e Rx de tórax. Os autores concluíram que que havia risco aumentado de patologia respiratória (nomeadamente silicose e bronquite crónica), tanto mais prováveis quanto pior a ventilação e menor o uso dos EPIs. Observacional
Analítico Este estudo teve por objetivo avaliar as alterações respiratórias em lapidadores de pedras preciosas. A mostra foi constituída por 93 Transversal trabalhadores de uma região do Sri Lanka $(100 \%$ da população trabalhadora) e os controlos foram trabalhadores de escritório dos serviços governamentais; o emparelhamento ocorreu por sexo e idade. Foi realizada espirometria em todos. Os autores concluíram que nestes profissionais existiam mais alterações respiratórias.

\section{Quadro 2- Principais riscos do setor da Ourivesaria, Joalharia e Relojoaria}

Secção

Riscos/

Fatores de Risco
Medidas de Proteção
Coletiva
Medidas de Proteção Individual 


\begin{tabular}{|c|c|c|c|}
\hline \multirow[t]{4}{*}{ Fundição } & $\begin{array}{l}\text { agentes químicos: } \\
\text { combustíveis (incêndio, } \\
\text { explosão, inalação de } \\
\text { gases tóxicos) }\end{array}$ & $\begin{array}{l}\text {-monitorização dos tempos } \\
\text { de cozedura } \\
\text {-sistemas de deteção e } \\
\text { extinção automática de } \\
\text { chamas } \\
\text {-exaustão para o exterior } \\
\text {-executar as tarefas mais } \\
\text { nocivas nos locais e } \\
\text { momentos com menos } \\
\text { trabalhadores expostos } \\
\text {-rotatividade } \\
\text {-disponibilizar as fichas de } \\
\text { segurança } \\
\text {-troca por agentes menos } \\
\text { tóxicos, se possível }\end{array}$ & $\begin{array}{l}\text {-máscara } \\
\text {-farda } \\
\text {-luvas }\end{array}$ \\
\hline & radiação infravermelha & $\begin{array}{l}\text {-executar as tarefas mais } \\
\text { nocivas nos locais e } \\
\text { momentos com menos } \\
\text { trabalhadores expostos } \\
\text {-rotatividade }\end{array}$ & $\begin{array}{l}\text { EPIs não } \\
\text { especificados }\end{array}$ \\
\hline & desconforto térmico & $\begin{array}{l}\text {-sistema de climatização } \\
\text {-ventilação adequada } \\
\text {-vestuário adequado } \\
\text {-disponibilização adequada } \\
\text { de água }\end{array}$ & $\begin{array}{l}\text {-farda adequada e } \\
\text { constituída por } \\
\text { várias peças } \\
\text { sobreponíveis }\end{array}$ \\
\hline & queimadura & $\begin{array}{l}\text {-isolamento de superfícies } \\
\text {-sinalização }\end{array}$ & $\begin{array}{l}\text { EPIs não } \\
\text { especificados } \\
\text {-luvas resistentes ao } \\
\text { calor }\end{array}$ \\
\hline \multirow[t]{2}{*}{ Trefilagem } & máquinas & $\begin{array}{l}\text {-mecanismos de bloqueio } \\
\text {-manutenção }\end{array}$ & $\begin{array}{l}\text { EPIs não } \\
\text { especificados }\end{array}$ \\
\hline & ruído & $\begin{array}{l}\text {-encapsulamento, uso de } \\
\text { materiais absorventes } \\
\text {-rotatividade de tarefas } \\
\text {-executar as tarefas mais } \\
\text { nocivas nos locais e } \\
\text { momentos com menos } \\
\text { trabalhadores expostos }\end{array}$ & -proteção auricular \\
\hline Moldagem & $\begin{array}{l}\text { asfixia e inalação de } \\
\text { agentes químicos }\end{array}$ & $\begin{array}{l}=(\text { tal como registado } \\
\text { anteriormente })\end{array}$ & $=$ \\
\hline
\end{tabular}




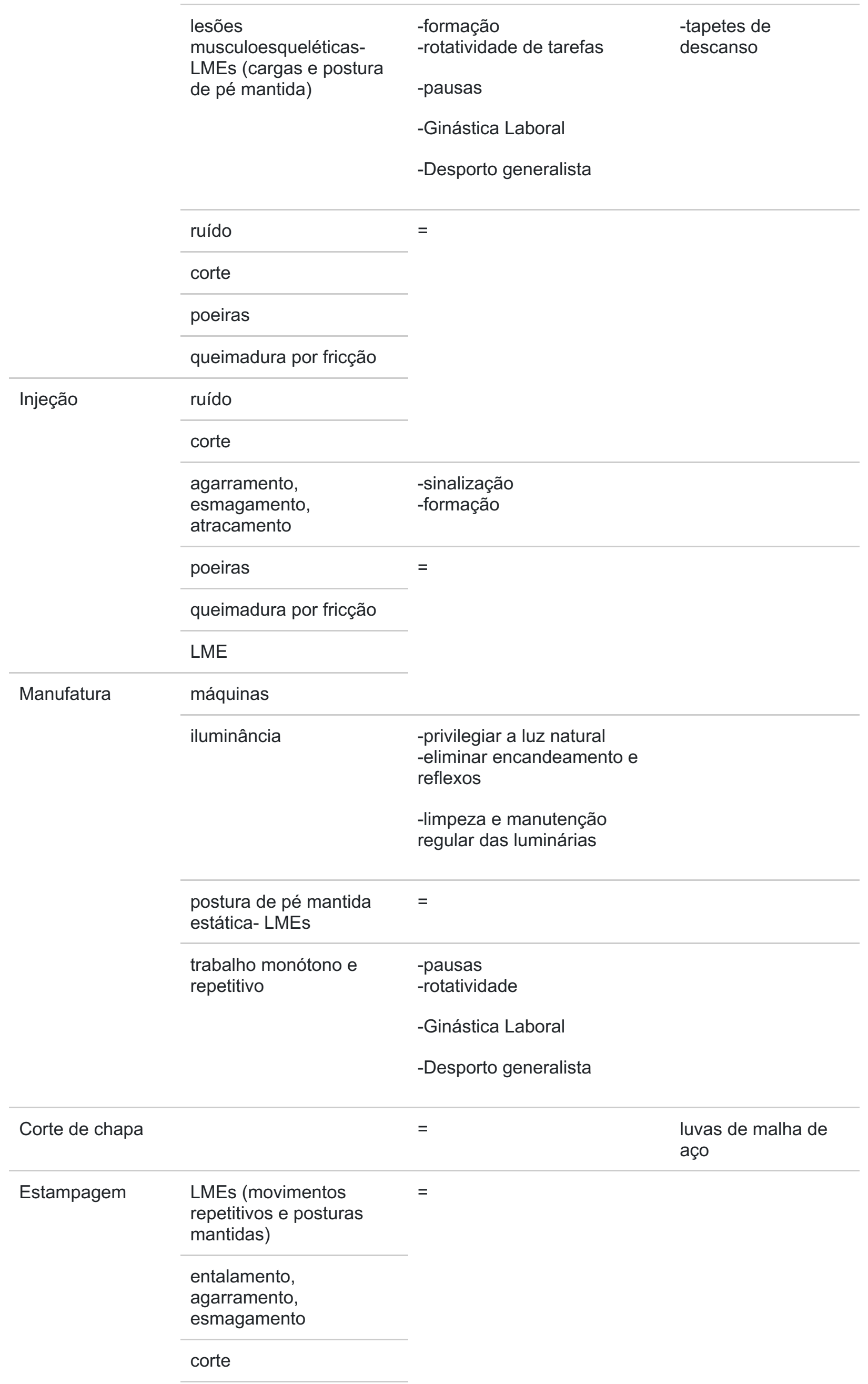




\begin{tabular}{|c|c|c|c|}
\hline & projeção de objetos & -manutenção adequada & $\begin{array}{l}\text {-óculos } \\
\text {-viseira }\end{array}$ \\
\hline & queimadura & $=$ & \\
\hline \multirow[t]{2}{*}{ Soldadura } & agentes químicos & & \\
\hline & $\begin{array}{l}\text { iluminância } \\
\text { desadequada- fadiga } \\
\text { visual }\end{array}$ & & \\
\hline \multirow[t]{4}{*}{ Lapidação } & ruído & $=$ & \\
\hline & $\begin{array}{l}\text { queda ao mesmo nível } \\
\text { (piso molhado) }\end{array}$ & $\begin{array}{l}\text {-limpeza } \\
\text {-arrumação }\end{array}$ & $\begin{array}{l}\text {-calçado } \\
\text { antiderrapante }\end{array}$ \\
\hline & vibrações & $\begin{array}{l}\text {-apoios anti vibrações } \\
\text {-menor tempo de exposição }\end{array}$ & $\begin{array}{l}\text {-luvas anti } \\
\text { vibrações }\end{array}$ \\
\hline & agentes químicos & $=$ & \\
\hline \multirow[t]{3}{*}{ Polimento } & poeiras & & \\
\hline & $\begin{array}{l}\text { Temperaturas elevadas/ } \\
\text { queimadura }\end{array}$ & & \\
\hline & ruído & & \\
\hline $\begin{array}{l}\text { Tratamento da } \\
\text { superfície de } \\
\text { metais }\end{array}$ & Agentes químicos & & \\
\hline \multirow{4}{*}{$\begin{array}{l}\text { Banhos de } \\
\text { galvanização }\end{array}$} & Agentes químicos & & \\
\hline & $\begin{array}{l}\text { LME (postura de pé } \\
\text { mantida) }\end{array}$ & & \\
\hline & Risco elétrico & -manutenção adequada & $\begin{array}{l}\text {-luvas e calçado } \\
\text { isolantes }\end{array}$ \\
\hline & derrames & Bacias de retenção & $\begin{array}{l}\text {-calçado e farda } \\
\text { impermeáveis e } \\
\text { resistentes }\end{array}$ \\
\hline Lavagem & Agentes químicos & $\begin{array}{l}\text {-ventilação } \\
\text {-formação }\end{array}$ & $\begin{array}{l}\text {-fato } \\
\text {-luvas } \\
\text {-óculos } \\
\text {-máscara }\end{array}$ \\
\hline Pintura & Agentes químicos & $=$ & \\
\hline $\begin{array}{l}\text { Armazenamento e } \\
\text { manuseamento de } \\
\text { substâncias } \\
\text { perigosas }\end{array}$ & $\begin{array}{l}\text {-LMEs } \\
\text {-queimaduras } \\
\text {-lesões oculares } \\
\text {-intoxicação } \\
\text {-explosão/ incêndio }\end{array}$ & & \\
\hline
\end{tabular}




\begin{tabular}{ll}
$\begin{array}{l}\text { Laboratório de } \\
\text { análises }\end{array}$ & $\begin{array}{l}\text {-temperaturas muito } \\
\text { elevadas/ queimadura } \\
\text {-lesões oculares }\end{array}$ \\
& $\begin{array}{l}\text {-intoxicação } \\
\text { Embalagem }\end{array}$ \\
\hline $\begin{array}{l}\text {-LMEs (posturas } \\
\text { desadequadas; repetição } \\
\text { do movimento) } \\
\text {-esforço visual }\end{array}$ \\
\hline Armazenamento & $\begin{array}{l}\text { Queda de objetos } \\
\text { Cargas }\end{array}$ \\
\hline Posturas desadequadas
\end{tabular}

(1)Licenciada em Medicina; Especialista em Medicina Geral e Familiar; Mestre em Ciências do Desporto; Especialista em Medicina do Trabalho; Presentemente a exercer nas empresas Medicisforma, Clinae, Servinecra e Serviço Intermédico; Diretora Clínica da empresa Quercia; Diretora da Revista Portuguesa de Saúde Ocupacional on line; Endereços para correspondência: Rua Agostinho Fernando Oliveira Guedes, 42 4420-009 Gondomar; s_monica_santos@hotmail.com.

(2)Mestre em Enfermagem Avançada; Especialista em Enfermagem Comunitária; Pós-graduado em Supervisão Clínica e em Sistemas de Informação em Enfermagem; Docente na Escola de Enfermagem (Porto), Instituto da Ciências da Saúde da Universidade Católica Portuguesa; Diretor Adjunto da Revista Portuguesa de Saúde Ocupacional on line; aalmeida@porto.ucp.pt.

Santos M, Almeida A. Ourivesaria, Joalharia e Relojoaria: principais Riscos e Fatores de Risco Laborais, Doenças Profissionais associadas e medidas de proteção recomendadas. Revista Portuguesa de Saúde Ocupacional on line. 2017, volume 3, 1-13. 